\title{
The anticancer drug tamoxifen is active against Trypanosoma cruzi in vitro but ineffective in the treatment of the acute phase of Chagas disease in mice
}

\author{
Danilo Ciccone Miguel ${ }^{1}$, Marcela Lencine Ferraz ${ }^{2}$, Rosana de Oliveira Alves ${ }^{2}$, \\ Jenicer KU Yokoyama-Yasunaka', Ana Claudia Torrecilhas', Alvaro José Romanha ${ }^{2}$, Silvia RB Uliana'1+ \\ ${ }^{1}$ Departamento de Parasitologia, Instituto de Ciências Biomédicas, Universidade de São Paulo, \\ Av. Prof. Lineu Prestes 1374, 05508-000 São Paulo, SP, Brasil \\ ${ }^{2}$ Laboratório de Parasitologia Celular e Molecular, Instituto de Pesquisas René Rachou-Fiocruz, Belo Horizonte, MG, Brasil
}

The activity of the antineoplastic drug tamoxifen was evaluated against Trypanosoma cruzi. In vitro activity was determined against epimastigote, trypomastigote and amastigote forms of CL14, Y and Y benznidazole resistant $\mathrm{T}$. cruzi strains. Regardless of the strain used, the drug was active against all life-cycle stages of the parasite with a half maximal effective concentration ranging from 0.7-17.9 $\mu \mathrm{M}$. Two experimental models of acute Chagas disease were used to evaluate the in vivo efficacy of treatment with tamoxifen. No differences in parasitemia and mortality were observed between control mock-treated and tamoxifen-treated mice.

Key words: chemotherapy - Chagas disease - selective oestrogen receptor modulator

Chemotherapy of Chagas disease remains a major challenge in the Americas. As a result of sustained campaigns of vector control, the number of new infections in endemic areas has decreased, but the disease still afflicts 10-15 million people in Latin America (Schofield et al. 2006). No satisfactory treatment for Trypanosoma cruzi infection is available (Pérez-Molina et al. 2009); currently used drugs are toxic and have disputable efficacy in the treatment of chronic infections (Marin-Neto et al. 2009).

Tamoxifen is a triphenylethylene that has been in clinical use for the treatment and chemoprevention of breast cancer since 1971 (Jordan 2003). It has been shown to inhibit the growth of promastigotes and intracellular amastigotes of several species of Leishmania (Miguel et al. 2007, 2009). Tamoxifen was also effective against the parasite in vivo, as shown in various experimental rodent models of visceral and cutaneous leishmaniasis. In all models tested, parasite burden and/or lesion progression decreased significantly after intraperitoneal administration of $20 \mathrm{mg} / \mathrm{kg} /$ day tamoxifen for 15 days (Miguel et al. 2008, 2009).

Leishmania and Trypanosoma belong to the Trypanosomatidae family, are genetically related and share many biochemical pathways, as shown by comparative analysis of their respective genomes (El-Sayed et al.

\footnotetext{
Financial support: FAPESP, FIOCRUZ, CNPq

DCM is the recipient of a post-graduate fellowship from FAPESP (05/59881-0).

DCM and MLF contributed equally to this work.

+ Corresponding author: srbulian@icb.usp.br

Received 1 July 2010

Accepted 1 September 2010
}

2005) and by comparative biochemical studies (Michels et al. 2006, Landfear 2008, Stuart et al. 2008). In this study, we evaluated the activity of tamoxifen against $T$. cruzi in vitro and in vivo.

The T. cruzi strains used were CL-14 (Brener \& Chiari 1963), Y (Silva \& Nussenzweig 1953) and a benznidazoleresistant line derived from the Y strain (BZR) (Murta \& Romanha 1998). Epimastigotes were grown in liver infusion-tryptose medium (LIT) supplemented with $10 \%$ fetal calf serum (FCS) and maintained at $25^{\circ} \mathrm{C}$ (Camargo 1964). The activity of tamoxifen (Sigma-Aldrich) against epimastigotes was assayed by counting the number of motile forms in a hemocytometer after incubating parasites with increasing concentrations of the drug for $24 \mathrm{~h}$.

To analyze the effect of tamoxifen on intracellular parasites, metacyclic trypomastigotes harvested from LIT cultures at the stationary growth phase were used to infect LLC-MK2 (rhesus monkey kidney, ATCC-CCL7) cells at a ratio of 50:1 parasites/host cell. Cultures were maintained at $34^{\circ} \mathrm{C}$ and $5 \% \mathrm{CO}_{2}$ in Roswell Park Memorial Institute (RPMI) medium (Sigma-Aldrich), supplemented with $2 \%$ FCS for $24 \mathrm{~h}$, washed to remove free parasites and then incubated for $48 \mathrm{~h}$ with increasing concentrations of tamoxifen. Infected cells were maintained at $34^{\circ} \mathrm{C}$ in an atmosphere of $5 \% \mathrm{CO}_{2}$ and the medium was replaced every $24 \mathrm{~h}$. After drug exposure, the untreated and treated infected cell cultures were fixed and stained with the Instant Prov kit (Newprov, Pinhais, Brazil). The number of infected host cells was determined using at least 400 host cells for two independent experiments run in triplicate.

Trypomastigotes were obtained from the blood of infected mice. To obtain sufficient numbers of parasites for drug susceptibility tests, these trypomastigotes were used to infect Vero cell cultures, which were maintained at $37^{\circ} \mathrm{C}$ and $5 \% \mathrm{CO}_{2}$ in Dulbecco's Modified Eagle's Medium supplemented with $10 \%$ FCS, as previously described (Santos 2008). Trypomastigotes released on the 
culture supernatant were recovered after 6-8 days, resuspended in RPMI without phenol red and incubated with increasing concentrations of tamoxifen for $24 \mathrm{~h}$ at $37^{\circ} \mathrm{C}$. The number of viable parasites was then assessed using the vital stain Alamar Blue (Invitrogen). Parasites were incubated with $10 \%$ Alamar Blue for $24 \mathrm{~h}$ at $37^{\circ} \mathrm{C}$ and the reduction of resazurin was monitored at $570 \mathrm{~nm}$ using $600 \mathrm{~nm}$ as a reference wavelength (Santos 2008). The percentage of viable cells was determined by comparison with control untreated cultures.

The half maximal effective concentration $\left(\mathrm{EC}_{50}\right)$ values for the T. cruzi populations were determined from sigmoidal regression of the concentration-response curves using Scientific Graphing and Analysis Software Origin 5.0. Experiments were performed in triplicate and repeated at least twice.

In vivo experiments were approved by the Ethical Committee for Animal Experimentation of the Institute of Biomedical Sciences of São Paulo University (approval certificates 033/07 and 067/08). Animals were bred, handled and maintained according to the Brazilian rules and regulations of animal experimentation. Acute infections were performed as described (Filardi \& Brener 1987). $\mathrm{BALB} / \mathrm{c}$ and Swiss Webster female and male mice were used (8-10 animals/experimental group). Infections were initiated by intraperitoneal inoculation of 5,000 T. cruzi $\mathrm{Y}$ strain tissue culture trypomastigotes/Swiss Webster mouse and 500 parasites/BALB/c mouse, due to the increased sensitivity of BALB/c mice to infection. Tamoxifen treatment was initiated on the 4th day of infection for Swiss Webster mice and on the 2nd day for BALB/c mice. Tamoxifen citrate was tested at $10,20,25$ and $50 \mathrm{mg} / \mathrm{kg} /$ day of drug equivalent for 15-20 days. Benznidazole (BZ) (Rochagan, Roche Co) was used as a reference drug at $100 \mathrm{mg} / \mathrm{kg}$ /day. Infected animals that received only saline were used as control groups. Parasitemia was assessed every other day from the 2nd day of infection by counting the trypomastigotes in a $5 \mu \mathrm{L}$ blood sample obtained from the tail vein. Surviving animals were monitored for 60 days and then subjected to hemoculture, used as a criterion of cure (Brener 1962). Tamoxifen citrate $(6 \mathrm{mg} / \mathrm{mL})$ and BZ $(6.25 \mathrm{mg} / \mathrm{mL})$ solutions were prepared in $150 \mathrm{mM}$ $\mathrm{NaCl}, \mathrm{pH}$ 7.2-7.4.

The table shows the in vitro activity of tamoxifen against $T$. cruzi strains and life stages. The drug was active against all $T$. cruzi life stages tested, with increased susceptibility noted for the infective mammalian stages, trypomastigotes and amastigotes. $\mathrm{EC}_{50}$ values calculated for epimastigotes of CL14, Y and BZR strains were similar, indicating homogeneous sensitivity between different strains and showing that resistance to BZ does not have an impact on sensitivity to tamoxifen.

The efficacy of tamoxifen in the control of acute infections was initially tested in female Swiss mice (Figs 1-3). Parasitemia peaks were reached at the 8th day after infection. The treatment of infected mice with 10,25 or $50 \mathrm{mg} / \mathrm{kg} /$ day of tamoxifen for 15-20 days did not alter the parasitemia curves as compared to control mock-treated groups, whereas parasitemia was undetectable in BZtreated mice (Figs 1-3). Previous experiments in leishma- niasis experimental models did not identify any differences between male and female responses to treatment with tamoxifen (Miguel et al. 2008). However, other research (de Souza et al. 2001) suggests that oestradiol may interfere in the outcome of $T$. cruzi infection in C57BL/6 female mice and, in a less pronounced way, in BALB/c and $\mathrm{C} 3 \mathrm{H}$ mice. Therefore, we decided to evaluate tamoxifen effectiveness in infected male Swiss mice (Fig. 4). No differences were detected in the response of male vs. female mice and tamoxifen treatment was completely ineffective in the control of parasitemia.

Acute $T$. cruzi infections in another mouse model were also performed. BALB/c mice infected with $T$. cruzi $\mathrm{Y}$ also developed parasitemia peaks at the 8th day post-infection. Male or female BALB/c mice treated with $20 \mathrm{mg} /$ $\mathrm{kg} /$ day tamoxifen for 15 days showed no reduction in parasitemia levels when compared to control animals. In contrast, parasitemia reached a peak in BZ-treated BALB/c mice around the 7th-8th day post-infection and became negative by the 23rd day post-infection (Fig. 5).

Another parameter assessed was the survival rate. While no mortality was detected in BZ-treated groups up to 60 days after infection (in Swiss Webster or BALB/c mice), animals treated with tamoxifen did not survive longer than control untreated groups, confirming the lack of antitrypanosomal activity of tamoxifen in these models of infection (Figs 1-5). Because there were no survivors in tamoxifen-treated and untreated groups, only the BZ-treated Swiss Webster mice were subjected to hemoculture. The cure rate was $70 \%$, as expected for the partially-resistant $T$. cruzi Y strain when infecting Swiss Webster mice.

The current chemotherapies of leishmaniasis and Chagas disease do not include drugs that are effective against both diseases. However, the novel anti-leishmanial activity of tamoxifen (Miguel et al. 2007, 2008, 2009) inspired curiosity about a possible common target between these organisms and led to the investigation of an anti-Trypanosoma effect. The results shown here indicate that tamox-

\section{TABLE}

In vitro activity of tamoxifen against

Trypanosoma cruzi strains and life stages

\begin{tabular}{lcc}
\hline Strain & Life stage & $\mathrm{EC}_{50} \pm \mathrm{SD}(\mu \mathrm{M})^{a}$ \\
\hline CL14 & Amastigote & $2.7 \pm 1.1$ \\
CL14 & Epimastigote & $17.9 \pm 3.3$ \\
$\mathrm{Y}$ & Epimastigote & $12.3 \pm 2.1$ \\
BZR & Epimastigote & $16.1 \pm 2.6$ \\
$\mathrm{Y}$ & Trypomastigote & $0.7 \pm 0.1$ \\
BZR & Trypomastigote & $0.7 \pm 0.1$ \\
\hline
\end{tabular}

$a$ : values are expressed as means \pm standard deviation (SD) of at least two independent experiments performed in triplicates. $\mathrm{EC}_{50}$ : tamoxifen effective concentration that decreases the number of viable parasites by $50 \%$ (in $24 \mathrm{~h}$ for epimastigotes and trypomastigotes and in $48 \mathrm{~h}$ for amastigotes). 
ifen is indeed active against both parasites. Data from in vitro tests, which demonstrated activity against the different $T$. cruzi life forms in the same order of magnitude as encountered for Leishmania spp, were initially very encouraging. However, despite the marked in vitro activity against two T. cruzi strains, tamoxifen did not prolong life or decrease parasitemia in experimental models of acute infection with $T$. cruzi. The therapeutic schemes in the present work included doses up to 2.5 -fold greater than the effective doses for the treatment of leishmaniasis (Miguel et al. 2008, 2009) and data presented here were obtained independently in two laboratories.

While the in vitro results indicate the shared presence of the tamoxifen biochemical target(s) in both organisms, undetermined factors prevent tamoxifen activity in vivo against $T$. cruzi. Whereas Leishmania preferentially para- sitises macrophages in the mammalian host and localizes preferentially in organs of the mononuclear phagocytic system, $T$. cruzi can inhabit most types of differentiated cells and has a wide organ distribution, especially in the acute form of the disease. Tamoxifen has been shown to accumulate in organs such as liver, bone marrow and adipose tissue, while only a minor portion of the drug remains in the serum (Lien et al. 1991). Differential tissue permeability and accumulation could explain the different outcomes of tamoxifen treatment. We cannot exclude that other factors, such as interference in immune-mediated defence mechanisms, are also of importance.

Beyond demonstrating that tamoxifen is ineffective against $T$. cruzi infections, these results also highlight the importance of using in vivo studies to validate new candidates for chemotherapy.
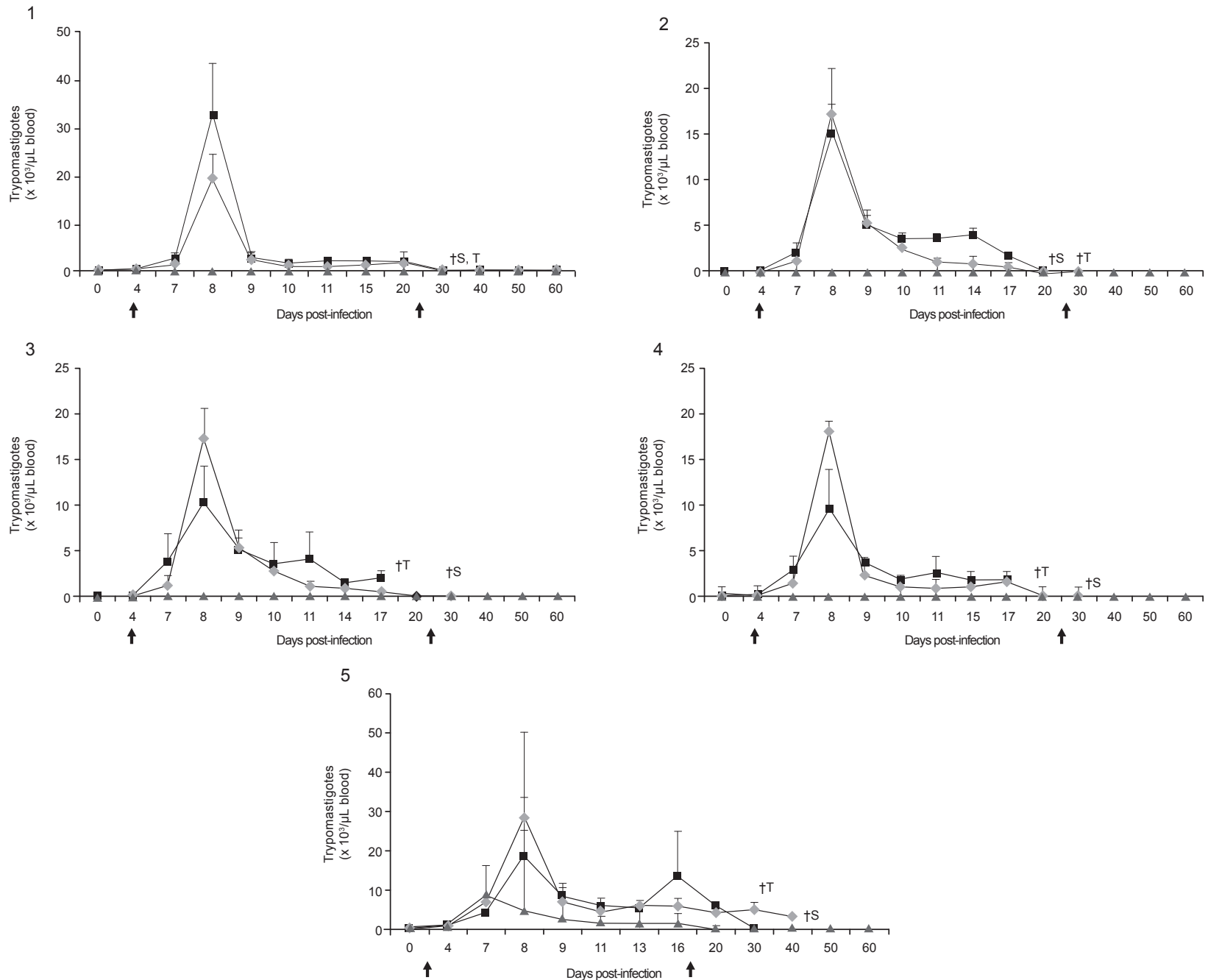

Figs 1-5: tamoxifen treatment of Trypanosoma cruzi acute infections in mice. Swiss Webster female (1-3) or male (4) mice and BALB/c female and male mice (5) were infected with $T$. cruzi Y strain. Treatment was started on the 4th day (1-4) or on the 2nd day (5) post-infection and parasitemia evaluated every other day by tail vein puncture. Animals were treated with tamoxifen (squares) at $10(1), 25(2), 50(3,4) \mathrm{or} 20 \mathrm{mg} / \mathrm{kg} / \mathrm{day}$ (5) for 15-20 days. Parasitemia curves from mock-treated animals (diamonds) and from animals that received $100 \mathrm{mg} / \mathrm{kg} / \mathrm{day}$ benznidazole (BZ) (triangles) were also obtained. Results are expressed as the mean of two independent experiments. Standard deviation is shown as a plus sided bar. The arrows indicate the period of treatment with tamoxifen or BZ. †S, †T: death of all animals from saline or tamoxifen-treated groups, respectively ( $\mathrm{n}=8-10$ animals per group). 


\section{ACKNOWLEDGEMENTS}

To Dr Ariel M Silber, for providing the CL14 Trypanosoma cruzi strain.

\section{REFERENCES}

Brener Z 1962. Therapeutic activity and criterion of cure on mice experimentally infected with Trypanosoma cruzi. Rev Inst Med Trop Sao Paulo 4: 389-396.

Brener Z, Chiari E 1963. Morphological variations observed in different strains of Trypanosoma cruzi. Rev Inst Med Trop Sao Paulo 5: 220-224.

Camargo EP 1964. Growth and differentiation in Trypanosoma cruzi. I. Origin of metacyclic trypanosomes in liquid media. Rev Inst Med Trop Sao Paulo 6: 93-100.

de Souza EM, Rivera MT, Araújo-Jorge TC, de Castro SL 2001. Modulation induced by estradiol in the acute phase of Trypanosoma cruzi infection in mice. Parasitol Res 87: 513-520.

El-Sayed NM, Myler PJ, Blandin G, Berriman M, Crabtree J, Aggarwal G, Caler E, Renauld H, Worthey EA, Hertz-Fowler C, Ghedin E, Peacock C, Bartholomeu DC, Haas BJ, Tran AN, Wortman JR, Alsmark UC, Angiuoli S, Anupama A, Badger J, Bringaud F, Cadag E, Carlton JM, Cerqueira GC, Creasy T, Delcher AL, Djikeng A, Embley TM, Hauser C, Ivens AC, Kummerfeld SK, Pereira-Leal JB, Nilsson D, Peterson J, Salzberg SL, Shallom J, Silva JC, Sundaram J, Westenberger S, White O, Melville SE, Donelson JE, Andersson B, Stuart KD, Hall N 2005. Comparative genomics of trypanosomatid parasitic protozoa. Science 309: 404-409.

Filardi LS, Brener Z 1987. Susceptibility and natural resistance of Trypanosoma cruzi strains to drugs used clinically in Chagas disease. Trans R Soc Trop Med Hyg 81: 755-759.

Jordan VC 2003. Tamoxifen: a most unlikely pioneering medicine. Nat Rev Drug Discov 2: 205-213.

Landfear SM 2008. Drugs and transporters in kinetoplastid protozoa. Adv Exp Med Biol 625: 22-32.

Lien EA, Solheim E, Ueland PM 1991. Distribution of tamoxifen and its metabolites in rat and human tissues during steady-state treatment. Cancer Res 51: 4837-4844.
Marin-Neto JA, Rassi A Jr, Avezum A Jr, Mattos AC, Rassi A, Morillo CA, Sosa-Estani S, Yusuf S, BENEFIT Investigators 2009. The BENEFIT trial: testing the hypothesis that trypanocidal therapy is beneficial for patients with chronic Chagas heart disease. Mem Inst Oswaldo Cruz 104 (Suppl. I): 319-324.

Michels PA, Bringaud F, Herman M, Hannaert V 2006. Metabolic functions of glycosomes in trypanosomatids. Biochim Biophys Acta 1763: 1463-1477.

Miguel DC, Yokoyama-Yasunaka JK, Andreoli WK, Mortara RA, Uliana SR 2007. Tamoxifen is effective against Leishmania and induces a rapid alkalinization of parasitophorous vacuoles harbouring Leishmania (Leishmania) amazonensis amastigotes. J Antimicrob Chemother 60: 526-534.

Miguel DC, Yokoyama-Yasunaka JK, Uliana SR 2008. Tamoxifen is effective in the treatment of Leishmania amazonensis infections in mice. PLoS Negl Trop Dis 2: e249.

Miguel DC, Zauli-Nascimento RC, Yokoyama-Yasunaka JK, Katz S, Barbiéri CL, Uliana SR 2009. Tamoxifen as a potential antileishmanial agent: efficacy in the treatment of Leishmania braziliensis and Leishmania chagasi infections. $J$ Antimicrob Chemother 63: 365-368.

Murta SM, Romanha AJ 1998. In vivo selection of a population of Trypanosoma cruzi and clones resistant to benznidazole. Parasitology 116: 165-171.

Pérez-Molina JA, Pérez-Ayala A, Moreno S, Fernández-González MC, Zamora J, López-Velez R 2009. Use of benznidazole to treat chronic Chagas' disease: a systematic review with a meta-analysis. J Antimicrob Chemother 64: 1139-1147.

Santos SL 2008. Análise proteômica da forma tripomastigota de uma população de Trypanosoma cruzi susceptivel e outra resistente ao benzonidazol, MSc Thesis, Instituto de Pesquisas René Rachou, Belo Horizonte, 72 pp.

Schofield CJ, Jannin J, Salvatella R 2006. The future of Chagas disease control. Trends Parasitol 22: 583-588.

Silva LHP, Nussenzweig V 1953. Sobre uma cepa de Trypanosoma cruzi altamente virulenta para o camundongo branco. Folia Clin Biol 20: 191-207.

Stuart K, Brun R, Croft S, Fairlamb A, Gürtler RE, McKerrow J, Reed S, Tarleton R 2008. Kinetoplastids: related protozoan pathogens, different diseases. J Clin Invest 118: 1301-1310. 